\title{
Inhibition of dipeptidyl peptidase IV with NVP-DPP728 increases plasma GLP-1 (7-36 amide) concentrations and improves oral glucose tolerance in obese Zucker rats
}

\author{
B. Balkan ${ }^{1}$, L. Kwasnik ${ }^{1}$, R. Miserendino ${ }^{1}$, J. J. Holst ${ }^{2}$, X. Li ${ }^{1}$ \\ ${ }^{1}$ Novartis Institute for Biomedical Research Summit, New Jersey, USA \\ ${ }^{2}$ Department of Medical Physiology, The Panum Institute, University of Copenhagen, Copenhagen, Denmark
}

\section{Abstract}

Aims/hypothesis. The potent incretin hormone glucagon-like peptide 1 (GLP-1) plays a pivotal role in prandial insulin secretion. In the circulation GLP-1 (7-36) amide is, however, rapidly $\left(\mathrm{t}_{1 / 2}: 1-2 \mathrm{~min}\right)$ inactivated by the protease dipeptidyl peptidase IV (DPPIV). We therefore investigated whether DPP-IV inhibition is a feasible approach to improve glucose homeostasis in insulin resistant, glucose intolerant fatty Zucker rats, a model of mild Type II (non-insulin-dependent) diabetes mellitus.

Methods. An oral glucose tolerance test was done in lean and obese male Zucker rats while plasma DPPIV was inhibited by the specific and selective inhibitor NVP-DPP728 given orally.

Results. Inhibition of DPP-IV resulted in a significantly amplified early phase of the insulin response to an oral glucose load in obese $f a / f a$ rats and restoration of glucose excursions to normal. In contrast, DPP-IV inhibition produced only minor effects in lean FA/? rats. Inactivation of GLP-1 (7-36) amide was completely prevented by DPP-IV inhibition suggesting that the effects of this compound on oral glucose tolerance are mediated by increased circulating concentrations of GLP-1 (7-36) amide. Reduced gastric emptying, as monitored by paracetamol appearance in the circulation after an oral bolus, did not appear to have contributed to the reduced glucose excursion.

Conclusion/interpretation. It is concluded that NVPDPP728 inhibits DPP-IV and improves insulin secretion and glucose tolerance, probably through augmentation of the effects of endogenous GLP-1. The improvement observed in prandial glucose homeostasis during DPP-IV inhibition suggests that inhibition of this enzyme is a promising treatment for Type II diabetes. [Diabetologia (1999) 42: 1324-1331]

Keywords NVP-DPP728, DPP-IV, GLP-1, insulin secretion, gastric emptying.
Control of prandial plasma concentrations of substrates, particularly glucose, is aided by incretins. Incretins are hormones released by the digestive tract in response to ingested nutrients [1]. The role of incretins is to sensitize beta cells to stimulation by glu-

Received: 13 April 1999 and in revised form: 1 July 1999

Corresponding author: B. Balkan, Novartis Institute for Biomedical Research, LSB 3517, 556 Morris Ave Summit, New Jersey 07901, USA.

Abbreviations: AMC, 7-Amino-4-methylcoumarin; CMC, carboxymethylcellulose; DPP-IV, dipeptidyl peptidase IV; GIP, gastric inhibitory polypeptide/glucose-dependent insulinotropic polypeptide; GLP-1, glucagon-like peptide 1 . cose, leading to an accelerated and augmented insulin response to absorbed glucose. The two most prominent incretins are gastric inhibitory polypeptide/glucose-dependent insulinotropic polypeptide (GIP) and glucagon-like peptide-1 (GLP-1). The first is released by $\mathrm{K}$ cells in the duodenum and jejunum [2] whereas GLP-1 is produced in L cells in the distal small intestine and in the colon [3]. Both GLP-1 and GIP augment glucose-stimulated insulin secretion [4, 5] and increase intracellular cAMP concentrations in beta cells [6]. Although some controversy exists regarding the relative importance of each of these incretins, both hormones have strong priming effects on the beta cells [7]. Several studies have shown that 
blockade of GLP-1 action with the GLP-1 receptor antagonist exendin (9-39) amide or with neutralizing antibodies results in increased glucose excursions after oral or intraduodenal glucose or meals while delaying or reducing the insulin responses [8-10]. This picture is reminiscent of the defect in insulin secretion in subjects with Type II (non-insulin-dependent) diabetes mellitus during an oral or intravenous glucose challenge and can be improved by replacing the early phase of insulin secretion $[11,12,13]$. The enhancement of the insulin response to oral nutrients by GLP-1 and GIP make GLP-1 and GIP attractive potential treatments for Type II diabetes.

In addition to its insulinotropic action, GLP-1 reduces gastric emptying [14] and inhibits glucagon secretion $[15,16]$, both further reducing the prandial glucose excursion. In Type II diabetic patients, GLP1 has been successfully used to normalize fasting and prandial glycaemia [15, 17-20]. As GLP-1 is a peptide, the application has, however, been limited to exploratory studies with intravenous infusion or buccal tablets [21].

Active GLP-1 (7-36) amide is rapidly transformed by dipeptidyl peptidase IV (CD26) into GLP-1 (9-36) amide which is inactive or antagonistic [22]. This cleavage leads to a half-life of the active GLP-1 (7-36) of 1 to $1.5 \mathrm{~min}$ in the circulation [23]. Recently, it has been shown that a substantial part of GLP-1 (7-36) amide released by the intestinal L cells is degraded in the surrounding capillaries [24]. This rapid inactivation is also responsible for the relative ineffectiveness of subcutaneously injected GLP-1 in the control of glycaemia in Type II diabetic patients [25] and will remain a major obstacle to any therapy relying on GLP-1 (7-36) amide.

We hypothesized that the inhibition of dipeptidyl peptidase IV(DPP-IV) would increase the plasma residence time of natural secreted GLP-1 [7-36) amide substantially and would thereby improve glycaemic control during a challenge. To test this hypothesis, we gave glucose orally to lean and obese Zucker rats after treatment with the DPP-IV inhibitor 1-[2-[(5-cyanopyridin-2-yl) amino] ethylamino] acetyl-2-cyano-(S)-pyrrolidine monohydrochloride salt (NVP-DPP728) and monitored their plasma GLP-1 response, and glucose and insulin excursions. NVP-DPP728 is a potent and selective orally available DPP-IV inhibitor (Fig. 1).

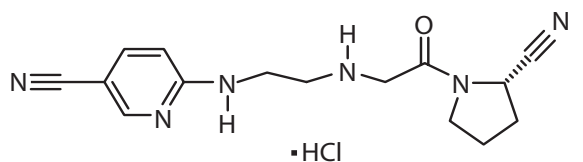

Fig. 1. Chemical structure of NVP-DPP728

\section{Materials and methods}

Animals and surgery. Lean (FA/?) and obese ( $f a / f a)$ male Zucker rats (Charles River, Wilmington, Mass., USA) were housed under a reversed light cycle (lights on 2000 hours to 0800 hours) with free access to tap water and standard rodent chow (Purina Labs, Richmond, Ind.,USA). The animals were aseptically implanted with a silastic catheter in the right jugular vein under Ketamine/Rompun/Acepromazin anaesthesia. The catheter was externalized in the nape of the neck and was filled with a solution of heparin and polyvinylpyrrolidone. The animals were allowed to recover from the surgery (regain of lost body weight) before the experiments.

Procedures. The animals were fasted for approximately $16 \mathrm{~h}$ (food removed 1700 hours on the day before the experiment). At -30 min on the day of the experiment, animals were orally dosed with the DPP-IV inhibitor NVP-DPP728 $(10 \mu \mathrm{mol} / \mathrm{kg}$, the dose had been chosen from pilot studies $)$ in vehicle $(0.5 \%$ carboxymethylcellulose (CMC) with $0.2 \%$ Tween 80 ) or vehicle alone. The NVP-DPP728 [26] was kindly supplied by E. Villhauer and J. Brinkman. The cannulas were then connected to sampling tubing. At -10 and $0 \mathrm{~min}$ two basal samples $(500 \mu \mathrm{l})$ were withdrawn. Glucose $(1 \mathrm{~g} / \mathrm{kg})$ was given by gavage after the second sample. Additional samples were withdrawn at 1 , $3,5,10,15,20,30,45$, and $60 \mathrm{~min}$. All samples were replaced by donor blood containing citrate and sodium-citrate as anticoagulant. Blood samples were collected in chilled Eppendorf tubes containing EDTA and trasylol to achieve final concentrations of $2.5 \mathrm{mg}$ EDTA and $1000 \mathrm{KIU}$ trasylol per $\mathrm{ml}$ of blood. Samples were centrifuged and plasma was stored at $-20^{\circ} \mathrm{C}$ until analyses.

A second experiment was done in obese Zucker rats to obtain samples for analysis of plasma concentrations of GLP-1 (7-36) amide and total GLP-1. The procedure was identical to the one described above except that larger samples $(1600 \mu \mathrm{l})$ were collected fewer times $(0,5,10,20,30,60 \mathrm{~min})$ and that paracetamol (4-acetomidophenol, Sigma, St. Louis, Mo., USA) was given (at $100 \mathrm{mg} / \mathrm{kg}$ i.e. $0.66 \mathrm{mmol} / \mathrm{Kg}$ ) together with the oral glucose load, to evaluate effects on gastric emptying. In addition to the six samples described above, smaller samples $(100 \mu \mathrm{l})$ collected at all the same times as in the first study were sampled to follow the appearance of the paracetamol in the plasma and to verify the glucose excursions from the first study.

Plasma analyses. Plasma glucose was analysed using a modified Sigma Diagnostics glucose oxidase kit (Sigma). Plasma immunoreactive insulin (IRI) concentrations were assayed by a double antibody RIA method using a specific anti-rat insulin antibody from Linco Research (St Louis, Mo., USA). The assay has a lower limit of detection of $30 \mathrm{pmol} / \mathrm{l}$ with intra-assay and inter-assay variations of less than $5 \%$.

Plasma GLP-1 concentrations were determined using radioimmunoassays specific for each end of the molecule. Amino-terminal immunoreactivity was measured using antiserum 93242 [21], which has a cross-reactivity of about $10 \%$ with GLP-1 (1-36) amide and of less than $0.1 \%$ with GLP-1 (8-36) amide and GLP-1 (9-36) amide. The detection limit is $5 \mathrm{pmol} /$ 1. High-performance liquid chromatography (HPLC) supports the use of RIAs with this specificity for determination of intact GLP-1 [22]. COOH-terminal immunoreactivity was determined using antiserum 89390 [27], which has an absolute requirement for the intact amidated COOH-terminus of GLP-1 (7-36) amide and cross-reacts less than $0.01 \%$ with $\mathrm{COOH}-$ terminally truncated fragments and $83 \%$ with GLP-1 (9-36) amide. For all assays, the intra-assay coefficient of variation 
Table 1. Basal plasma variables of obese $(f a / f a)$ and lean $(\mathrm{FA} /$ ?) Zucker rats after vehicle $(\mathrm{CMC})$ or compound $(10 \mu \mathrm{mol} / \mathrm{kg})$ treatment

\begin{tabular}{lllllcc}
\hline Strain & Treatment & $n$ & $\begin{array}{l}\text { Body weight } \\
(\mathrm{g})\end{array}$ & $\begin{array}{l}\text { Plasma glucose } \\
(\mathrm{mmol} / \mathrm{l})\end{array}$ & $\begin{array}{l}\text { Plasma IRI } \\
(\mathrm{pmol} / \mathrm{l})\end{array}$ & $\begin{array}{l}\text { DPP-IV activity } \\
(\mathrm{mU} / \mathrm{ml})\end{array}$ \\
\hline$f a / f a$ & Vehicle & 8 & $385 \pm 17$ & $6.4 \pm 0.4$ & $2298 \pm 534$ & $5.8 \pm 1.4$ \\
$f a / f a$ & NVP-DPP728 & 8 & $373 \pm 19$ & $5.1 \pm 0.4^{\mathrm{b}}$ & $1674 \pm 462$ & $0 \pm 0^{\mathrm{c}}$ \\
FA/? & Vehicle & 6 & $288 \pm 10^{\mathrm{a}}$ & $4.4 \pm 0.1^{\mathrm{a}}$ & $209 \pm 24^{\mathrm{a}}$ & $3.7 \pm 0.8$ \\
FA/? & NVP-DPP728 & 7 & $286 \pm 7$ & $4.1 \pm 0.2$ & $147 \pm 14$ & $0 \pm 0^{\mathrm{b}}$
\end{tabular}

Data are absolute values \pm SEM of 0 min. samples in the respective unit as indicated by the column header. Data were analysed by two-way ANOVA for strain effects $\left({ }^{\mathrm{a}}: p<0.01\right)$ and treatment effects $\left({ }^{\mathrm{b}}: p<0.05,{ }^{\mathrm{c}}: p<0.01\right.$, vs, the respective vehicle-treated control group by Bonferroni correction). Values that differ at the $p<0.01$ level are marked ${ }^{\mathrm{c}}$ and ${ }^{\mathrm{d}}$, respectively. The number of animals per group is given in column $n$. Vehicle or compound was given orally at $-30 \mathrm{~min}$ was less than $6 \%$. Plasma samples were extracted with $70 \%$ ethanol ( $\mathrm{vol} / \mathrm{vol}$, final concentration) before assay, giving recoveries of $75 \%$ [28]. The assay for GLP-1 (7-36) amide resulted in higher values than the $\mathrm{COOH}$-terminal assay. For this reason all data for GLP-1 responses are depicted as change from basal levels.

Paracetamol concentrations were determined in plasma samples using a fluorometric kit (No 430-A, Sigma). Briefly, plasma proteins are removed with trichloroacetic acid, followed by reaction of paracetamol with nitrous acid, yielding nitro-derivatives which assume a deep yellow colour in alkaline medium. The sample is read in a spectrophotometer at $430 \mathrm{~mm}$ and the absorbance is proportional to the paracetamol concentration. Plasma DPP-IV activity was measured using an assay based on a modification described previously [29] of a published method [30]. Briefly, aliquots of plasma were incubated with substrate (Gly-Pro-AMC, where AMC is 7-amino4-methylcoumarin (Bachem, King of Prussia, Pa., USA). Free AMC generated proportionally to DPP-IV activity was measured by fluorimetry. Catalytic DPP-IV activity in plasma is expressed as $\mathrm{mUnit} / \mathrm{ml}$ ( 1 Unit $=1$ umol substrate cleaved per min). The study was approved by the Novartis Animal Care and Use Committee, and is in accordance with the NIH guidelines for laboratory animal care.

Data are expressed as means \pm SEM. Statistical analysis was by $t$ test. All statistical significances reflect two-tailed testing unless stated otherwise. Because insulin responses were expected to be increased and glucose excursions decreased in animals treated with drugs, one-tailed $t$ tests were done for area under the curve (AUC) results. Basal data for the animals in the different groups (Table 1) were tested by two-way ANOVA followed by Bonferroni correction.

A difference was considered statistically significant when $p$ was less than 0.05 .

\section{Results}

Basal variables of the animals in this study are described in Table 1 . Obese $(f a / f a)$ rats were heavier than their lean counterparts. The obese animals displayed a moderate increase of fasting glycaemia, compared with the lean rats, in the presence of pronounced hyperinsulinaemia. This is indicative of profound insulin resistance in these animals. Inhibition of DPP-IV with NVP-DPP728 lowered basal plasma glucose concentrations in obese rats by $20 \%$ $(p<0.05)$ but had no effect in the lean rats. Inhibition of plasma DPP-IV activity did reduce basal plasma insulin concentrations by about $30 \%$ in both lean and obese rats but this was not statistically significant due to large interanimal variability. Treatment with NVP-DPP728 led to complete inhibition of plasma DPP-IV activity.

Giving $1 \mathrm{~g} / \mathrm{kg}$ glucose orally to lean and obese Zucker rats evoked a pronounced glucose excursion in both groups of animals (Fig.2). Obese rats treated with vehicle reached, however, higher peak glucose concentrations (mean of individual peak glucose concentrations fa/fa: $15.3 \pm 0.4 \mathrm{mmol} / \mathrm{l}, \quad \mathrm{FA} / ?: \quad 9.3 \pm$ $0.3 \mathrm{mmol} / 1, p<0.0001$ ) with a glucose excursion of approximately twice the size of lean animals similarly treated (Fig. 3). This was in spite of a considerably increased insulin response (Fig. 2). When plasma DPPIV activity was fully inhibited (Table 1, Fig. 4), the insulin response to the oral glucose challenge was increased in obese and to a lesser extent in lean Zucker rats (Fig.2). Concomitantly the plasma glucose concentrations were lower in DPP-IV-inhibited obese Zucker rats, with lower peak glucose concentrations than in falfa rats treated with vehicle $(12.1 \pm$ $1.0 \mathrm{mmol} / \mathrm{l}$ vs $15.3 \pm 0.4 \mathrm{mmol} / 1, p<0.01)$. The change in the glucose profile occurred predominantly in the latter part of the test with glucose excursions significantly different between $f a / f a$ vehicle and $f a / f a$ NVPDPP728 at times 20,30 and $45 \mathrm{~min}(p<0.05)$. The improvement in glucose tolerance was less pronounced in the lean Zucker rats but the pattern of the response to DPP-IV inhibition was similar to that in obese animals. These results are also evident from the integrated insulin responses and glucose excursions (Fig. 3).

When plasma insulin concentrations were expressed as a percent of individual basal concentrations, a method that takes account of the compensated insulin resistance in normoglycaemic animals and reflects the secretory response itself, it is apparent that the obese rats treated with vehicle have a reduced insulin response to the oral glucose load compared with the lean control rats (Fig. 2). After treatment with NVPDPP728 the relative insulin response in lean and obese animals was, however, similarly increased. 

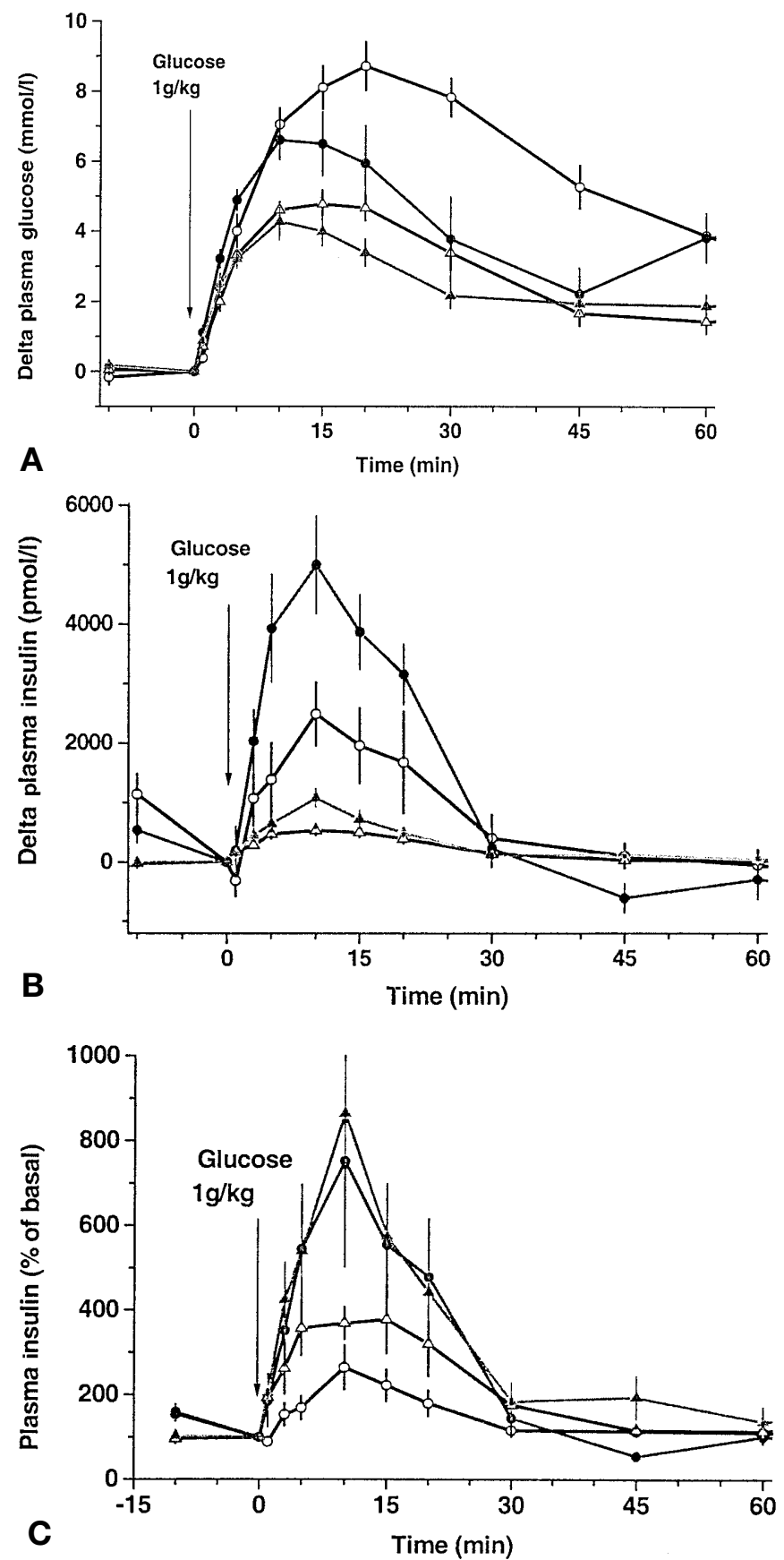

Fig. 2A-C. Changes in plasma (A) glucose concentrations (B) immunoreactive insulin (IRI) concentrations and (C) relative change in plasma IRI concentrations in obese $(\mathrm{fa} / \mathrm{fa})$ and lean (FA/?) Zucker rats $(n=6-8)$ after vehicle (CMC) or compound $(10 \mu \mathrm{mol} / \mathrm{kg})$, was given at $-30 \mathrm{~min}$. All animals received $1 \mathrm{~g} / \mathrm{kg}$ glucose orally at $0 \mathrm{~min}$. The data are displayed as means \pm SEM of individual delta plasma glucose concentrations from basal (pre-glucose, 0 min.) levels. In $\mathbf{C} \longrightarrow \triangle \mathrm{FA} /$ ? vehicle $\longrightarrow$ FA/? NVP-DPP728 - $-f a / f a$ vehicle - fa/fa NVP-DPP728. The data are displayed as mean \pm SEM per cent of individual basal (pre-glucose, 0 min.) plasma IRI concentrations
In the second part of the study, the experiment was repeated in obese $f a / f a$ rats to obtain samples for plasma GLP-1 determination and to obtain an index of gastric emptying through measurement of paracetamol appearance in the circulation. During this study plasma glucose concentrations were measured in all samples to assure that the study closely resembled the first experiment. Basal plasma GLP-1 (7-36 and 9-36) amide concentrations did not differ between $\mathrm{fal}$ $f a$ rats treated with vehicle $(6.2 \pm 2.4 \mathrm{pmol} / \mathrm{l})$ and those treated with DPP-IV inhibitor $(3.4 \pm 1.0 \mathrm{pmol} / \mathrm{l}, \mathrm{NS})$. Both groups of rats had a clear GLP-1 response to the oral glucose challenge (Fig. 5). Although the increment in DPP-IV inhibited rats was almost twice that in control animals, this effect was not statistically significant due to a large degree of interanimal variation. The basal concentrations of active GLP-1 (7-36) amide in rats treated with NVP-DPP728 $(20.3 \pm 2.3$ $\mathrm{pmol} / \mathrm{l})$ were higher than in control rats $(11.8 \pm 2.2$ pmol/l, $p<0.05)$. Whereas the GLP-1 (7-36) amide response to the oral challenge in control $f a / f a$ rats was blunted compared with the total GLP-1 release, the rise in GLP-1 (7-36) amide in animals treated with DPP-IV inhibitor was pronounced. In $f a / f a$ rats treated with vehicle $24 \pm 17 \%$ of total GLP-1 (7-36) amide at the peak $(5-10 \mathrm{~min})$ is present in the active form (calculated from the mean of values obtained at 5 and $\left.10 \mathrm{~min} \frac{\mathrm{GLP}-1(7-36)}{\mathrm{GLP}-1} \times 100 \%\right)$. In contrast all of the GLP-1 is present as the intact form in rats treated with NVP-DPP728 $(109 \pm 20 \%, p=0.01)$.

During the second study, paracetamol was given orally together with the glucose solution to obtain an index of gastric emptying. Plasma paracetamol concentrations in the falfa rats are depicted in Figure 6. The curves for vehicle and $f a / f a$ rats treated with DPP-IV inhibitor are superimposable except for a significant difference $(p=0.03)$ at $20 \mathrm{~min}$ after giving glucose and paracetamol. The area under the paracetamol curve was not different between NVPDPP728-treated (AUC $39.5 \pm 1.3 \mathrm{mmol} / \mathrm{l} \cdot 120 \mathrm{~min}$ ) and $f a / f a$ rats treated with vehicle $(42.6 \pm 1.3 \mathrm{mmol} /$ $1 \cdot 120 \mathrm{~min}, \mathrm{NS})$.

\section{Discussion}

Our aim was to study the effects of DPP-IV inhibition on insulin secretion, glycaemic control and GLP-1 concentrations during an oral glucose challenge in a model of impaired glucose tolerance. The results indicate that treatment with NVP-DPP728, an inhibitor of DPP-IV, preserves the active GLP-1 (7-36) amide in circulation and augments early insulin response to an oral glucose challenge. As a consequence, the glucose excursion in obese Zucker is nearly restored to normal in $f a / f a$ rats. The effects of DPP-IV inhibition were much less pronounced in lean Zucker rats. 


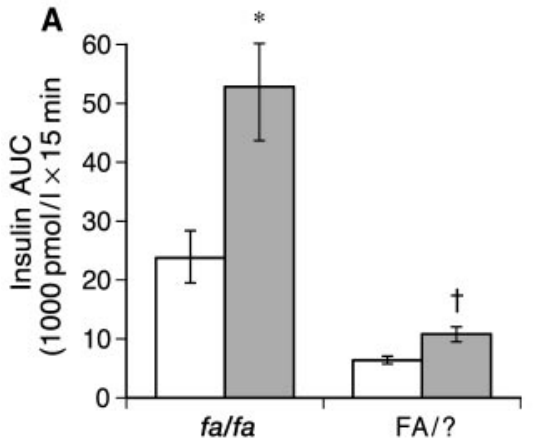

Fig. 3 A, B. Integrated changes in plasma immunoreactive insulin (A) and plasma glucose concentrations (B) during an oral glucose tolerance test in obese $(f a / f a)$ and lean (FA/?) Zucker rats $(n=6-8)$ after vehicle (CMC) or compound (NVP-DPP728, $10 \mu \mathrm{mol} / \mathrm{kg}$ given at $-30 \mathrm{~min}$. All animals received $1 \mathrm{~g} / \mathrm{kg}$ glucose orally at $0 \mathrm{~min}$. The data are displayed as means \pm SEM of incremental areas under the curves (AUC) calculated by the trapezoidal rule. Insulin AUC reflects the early phase of insulin secretion (0-15 min.), glucose AUC 0-45 min. Statistically significant differences are presented as *: $p<0.05$ vs $f a / f a$ vehicle, $\mathrm{t}: p<0.05$ vs, FA/? vehicle and \#: $p=0.06$ vs FA/? vehicle. $\square$, vehicle; $\square$ NVP-DPP728

Glucagon-like peptide- 1 has received a large amount of attention in recent years because of its potential as a treatment for Type II diabetes [31]. This is mainly based on its potent sensitization of pancreatic beta cells to stimulation with glucose and its inhibition of glucagon secretion $[4,5]$. Since impaired insulin secretion to a glucose challenge is a hallmark of Type II diabetes [32], GLP-1-based treatment would target one of the fundamental defects of the disease. A GLP-1-based therapy is also attractive because the responsiveness of beta cells to GLP-1 is maintained in Type II diabetic subjects [33]. Although many studies have shown the benefit of GLP-1 treatment on glycaemic control in Type II and Type I diabetic patients, poor bioavailability is a major drawback for the clinical use of GLP-1.

Furthermore, because the half-life of active GLP-1 in the circulation is in the order of 1 to $2 \min [22,34]$ the feasibility of GLP-1 itself as a therapy is limited. The short half-life is exclusively dependent on the dipeptidylpeptidase IV-mediated cleavage of two amino-terminal amino acids of GLP-1 (7-36) amide to generate the inactive, or antagonistic [35], fragment GLP-1 (9-36) amide. This rapid degradation of GLP-1 (7-36) amide leads to the prediction that only approximately $20 \%$ of endogenous or exogenous GLP-1 is circulating in the active form. This estimate is supported by this and other studies [21-23, 36]. Active GLP-1 (7-36) amide concentrations necessary to achieve improvements in glycaemic control are in the range of $20-30 \mathrm{pmol} / \mathrm{l}$, the concentrations found postprandially for total GLP-1. We hypothe-

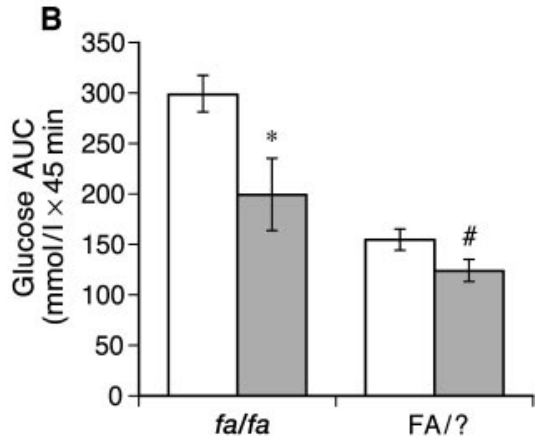

sized therefore that inhibition of DPP-IV activity would raise the low circulating concentrations of active GLP-1 (7-36) amide after a nutrient challenge to those that are more effective and would thereby improve glycaemic control.

The effects of NVP-DPP728, an inhibitor of DPPIV, was investigated in obese Zucker rats $(f a / f a)$, a well-characterized model of obesity and insulin resistance. The primary genetic defect resides in the receptor for the $o b$ gene product (leptin, [37]). As a consequence, the feedback loop from the adipocytes to the central nervous system and peripheral organs is impaired, leading to hyperphagia, increased adipogenesis, hyperinsulinaemia, obesity, impaired glucose tolerance, and insulin resistance [38-40]. Our study confirmed these characteristics and further indicates that the obese Zucker rats fail to increase insulin secretion in proportion to the prevailing insulin resistance (as also indicated by the tenfold hyperinsulinaemia found in the basal state compared with lean rats, Fig. 4). Consequently, plasma glucose concentrations after the oral glucose load reach higher peak values than in the lean control group and remain high for a prolonged period of time, both characteristics of human impaired glucose tolerance.

Complete DPP-IV inhibition augmented the insulin response to an oral glucose challenge in glucose intolerant, obese Zucker rats. It also resulted in a pronounced reduction in the glucose excursion. Two details are noteworthy. Firstly, the statistically significant increase in insulin concentrations could first be seen $5 \mathrm{~min}$ after giving glucose in animals treated with DPP-IV inhibitor. Second, no differences between $f a / f a$ rats treated with vehicle or inhibitor could be found in the glucose concentrations until approximately $20 \mathrm{~min}$ after the glucose bolus. These data are congruent with the hypothesis that the augmented insulin response is causal to the reduction in the glucose excursions. Furthermore, because the rise in glucose concentration is unaffected by DPP-IV inhibition, this suggests that the rate of gastric emptying or absorption is not likely to have affected the glucose appearance. To corroborate these conclusions we added paracetamol to the glucose load in the second study. Paracetamol is absorbed in the duodenum but not in the stomach [41]. As such it is a suitable 


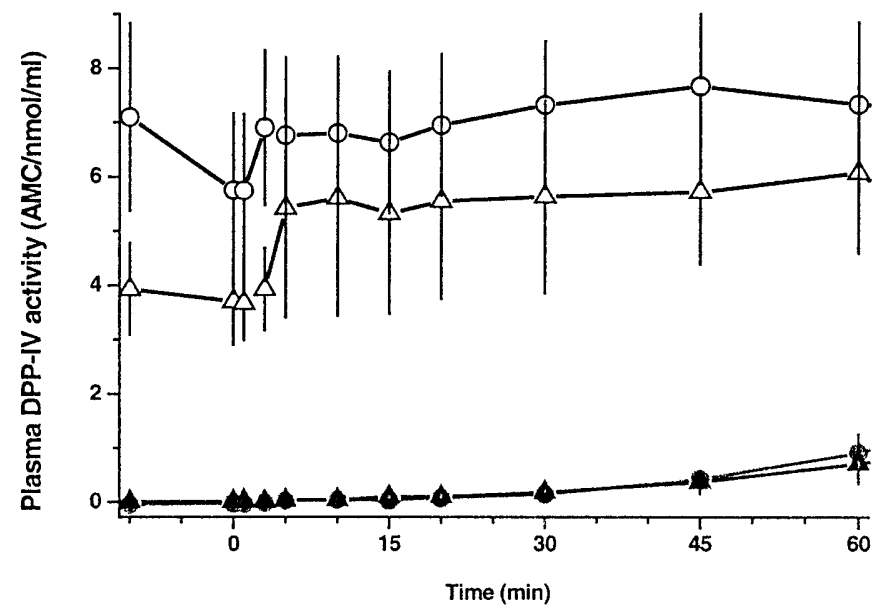

Fig. 4. Plasma DPP-IV activity in obese ( $f a / f a)$ and lean (FA/?) Zucker rats $(n=6-8)$ after vehicle (CMC) or compound (NVP$\mathrm{DPP} 728,10 \mu \mathrm{mol} / \mathrm{kg})$ given at $-30 \mathrm{~min}$. All animals received $1 \mathrm{~g} / \mathrm{kg}$ glucose orally at $0 \mathrm{~min}$. The data are displayed as means \pm SEM of individual activity. $\longrightarrow-\mathrm{fa} / \mathrm{fa}$ vehicle $\longrightarrow-\mathrm{fa} / \mathrm{fa}$ NVP-DPP728 $\backsim$ FA/? vehicle $\longrightarrow$ FA/? NVP-DPP728

marker for gastric emptying of liquids [42]. The lack of any major delay in the paracetamol appearance indicates that DPP-IV inhibition had a very small effect, if any, on gastric emptying and that the reduction in glucose excursion is not likely to be the result of reduced absorption. Indeed in a control experiment in which cholecystokinin was given to delay gastric emptying the paracetamol appearance (and the rise in plasma glucose) was considerably delayed (data not shown).

These results differ from those in studies in which GLP-1 was given exogenously which report effects on gastric emptying [35, 43, 44]. Furthermore, the degradation product GLP-1 (9-36) amide has been reported to antagonize GLP-1 (7-36) amide-induced inhibition of gastric motility [35]. Thus, it could be expected that during DPP-IV inhibition, with higher GLP-1 (7-36) and lower antagonist concentrations the delayed gastric emptying effects would be prominent.

Three theoretical explanations for this difference can be given. Firstly, humans and rodents possibly rely to a different degree on GLP-1 for regulating gastric emptying and with different sensitivity. We recently observed that supra pharmacological doses of GLP-1 (7-36) amide injected intravenously at the time of the oral glucose challenge substantially delay paracetamol appearance [45], suggesting that in the present study GLP-1 did not reach sufficient concentrations to result in delayed gastric emptying. Secondly, basal gastric motility is relatively low, and may not be required for emptying of a solely liquid nutrient load. Third, most of the glucose solution may have been in the intestine by the time glucose-stimulated GLP-1 release could affect gastric motility. Thus, the lack of effect of DPP-IV inhibition on gastric empty-
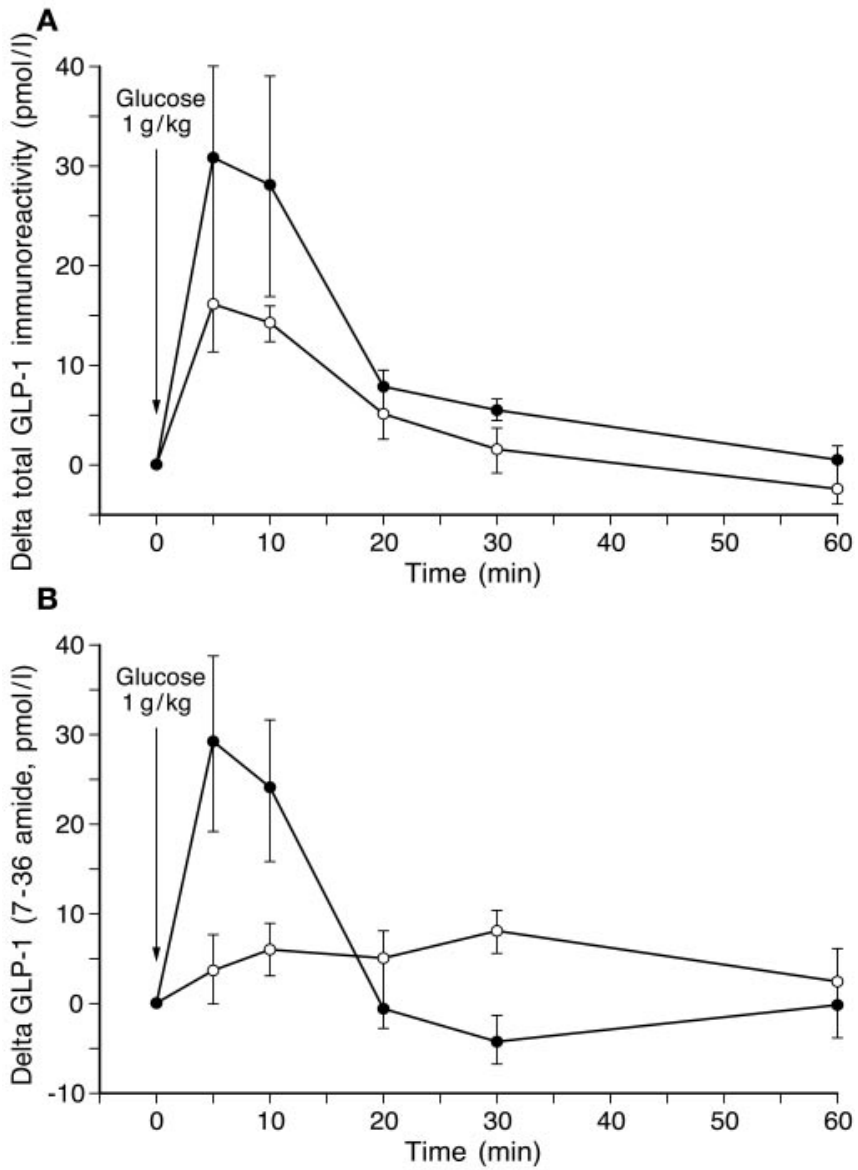

Fig. 5A, B. Changes in plasma immunoreactive GLP-1 (7-36) amide (A) and total plasma GLP-1 immunoreactivity (B) during an oral glucose tolerance test in obese $(\mathrm{fa} / \mathrm{fa})$ Zucker rats $(n=8)$ after vehicle (CMC) or compound (NVP-DPP728, $10 \mu \mathrm{mol} / \mathrm{kg}$ ) given at $-30 \mathrm{~min}$. All animals received $1 \mathrm{~g} / \mathrm{kg}$ glucose orally at $0 \mathrm{~min}$. The data are displayed as means + SEM of individual delta plasma GLP-1 concentrations from basal (pre-glucose, 0 min.) levels. $\longrightarrow-$ vehicle $\longrightarrow$ NVP DPP 728

ing in the current study could well be limited to the applied nutritional challenge.

The results of this study confirm the observations by ourselves and others [46, 47] that DPP-IV inhibition considerably improves oral glucose tolerance in Zucker rats. We extend this finding by showing that endogenously secreted GLP-1 (7-36) amide is highly preserved in the circulation during DPP-IV inhibition, suggesting that the improved insulin response and glucose tolerance is a result of increased GLP-1 action on the pancreas. The data further suggest that the improved glucose tolerance is not a result of reduced gastric emptying. The paracetamol data further indicate that a large part of the glucose load is emptied into the small intestine within the first $20 \mathrm{~min}$ after the glucose load is given. This is supported by the profile of total GLP-1 in the plasma. Peak concentrations of GLP-1 are achieved 5 min after glucose is given and total plasma GLP-1 concentra- 


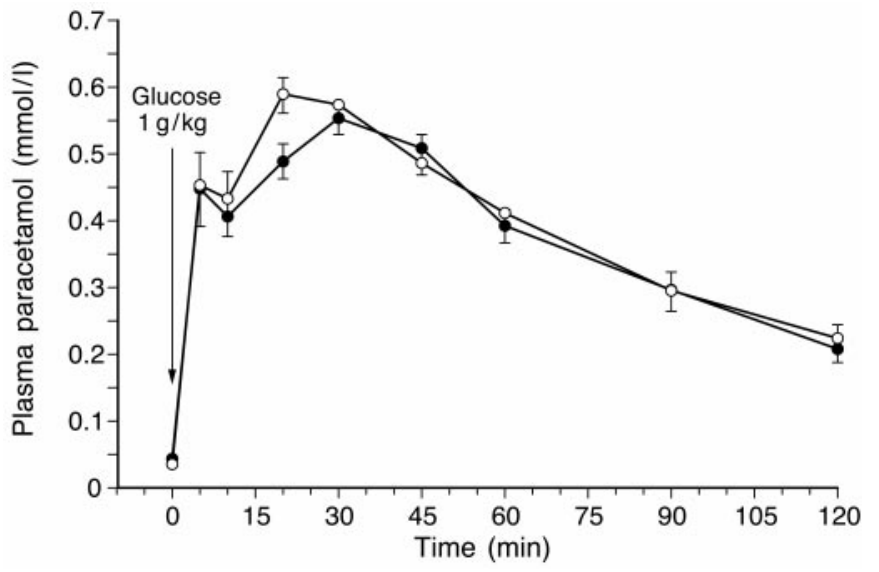

Fig. 6. Changes in plasma paracetamol concentrations during an oral glucose tolerance test in obese $(f a / f a)$ Zucker rats $(n=8)$ after vehicle (CMC) or compound (NVP-DPP728, $10 \mu \mathrm{mol} / \mathrm{kg}$ ). Animals were administered vehicle or compound at $-30 \mathrm{~min}$. All animals received $1 \mathrm{~g} / \mathrm{kg}$ glucose and $100 \mathrm{mg} / \mathrm{kg}$ paracetamol orally at $0 \mathrm{~min}$. The data are displayed as mean$\mathrm{S} \pm \mathrm{SEM}$ of individual plasma paracetamol concentrations $\longrightarrow$ - vehicle $\longrightarrow$ NVP DPP 728

tions are close to basal at $20 \mathrm{~min}$. Considering that the half-life of elimination of total GLP-1 from the circulation is 3-3.5 min in pigs [29] still several times longer than the half-life of the active GLP-1 (7-36) amide), the release of GLP-1 from the L cells probably ceased not long after the 10 min sample. The results clearly indicate that the secreted GLP-1 (7-36) amide is highly preserved during DPP-IV inhibition and that the augmentation of the insulin response to the oral glucose challenge coincides in time with the GLP-1 release.

It is known that DPP-IV degrades peptides with a proline or alanine in the penultimate $\mathrm{N}$-terminal residues [48]. This includes not only GLP-1 (7-36) amide and GIP but also peptide YY and neuropeptide Y (NPY). It can be hypothesized that GIP has played a part in the effects of DPP-IV inhibition observed here. This study was not, however, designed to address this question. In addition, a larger number of peptides are potential substrates, but the actual role of DPP-IV in the regulation of the activity of these peptides is not known. The potential effects of DPPIV inhibition on other peptides have also been addressed elsewhere [31].

In conclusion, treatment with NVP-DPP728 during an oral glucose tolerance test completely inhibited plasma DPP-IV activity, highly preserved the endogenously secreted GLP-1 (7-36) amide, augmented the insulin response and all but restored the glucose excursion to normal in glucose intolerant, obese Zucker rats. The results suggest that DPP-IV inhibition could be a promising treatment for prandial hyperglycaemia in Type II diabetes especially in mild diabetes where the risk of, potentially fatal, hypogly- caemia is greatest when traditional insulin secretagogues, such as sulphonylureas are used.

Acknowledgements. Expert assistance of L. Albaek, A. Bolat, C. Crisafi, T. Hughes, M. Mone, J. Olejarczyk-Gurkan is gratefully acknowledged.

\section{References}

1. Creutzfeldt W (1979) The incretin concept today. Diabetologia 16: $75-85$

2. Brown JC, Buchan AM, McIntosh CH, Pederson RA (1989) Gastric inhibitory polypeptide. Schultz S. G., Makhlouf, G. M., and Rauner, B.B. Handbook of Physiology, Section 6. Bethesda, American Physiological Society, pp 403-430

3. Holst JJ (1997) Enteroglucagon. Annu Rev Physiol 59: 257-271

4. Goeke R, Wagner B, Fehmann HC, Goeke B (1993) Glucosedependency of the insulin stimulatory effect of glucagon- like peptide-1 (7-36) amide on the rat pancreas. Res Exp Med (Berl) 193: 97-103

5. Fridolf T, Bottcher G, Sundler F, Ahren B (1991) GLP-1 and GLP-1(7-36) amide: influences on basal and stimulated insulin and glucagon secretion in the mouse. Pancreas 6:208-215

6. Lu M, Wheeler MB, Leng XH, Boyd AE 3rd (1993) The role of the free cytosolic calcium level in beta-cell signal transduction by gastric inhibitory polypeptide and glucagon-like peptide I(7-37). Endocrinology 132: 94-100

7. Fehmann HC, Goeke R, Goeke B, Bachle R, Wagner B, Arnold R (1991) Priming effect of glucagon-like peptide-1 (7-36) amide, glucose- dependent insulinotropic polypeptide and cholecystokinin- 8 at the isolated perfused rat pancreas. Biochim Biophys Acta 1091: 356-363

8. Kolligs F, Fehmann HC, Goke R, Goke B (1995) Reduction of the incretin effect in rats by the glucagon-like peptide 1 receptor antagonist exendin (9-39) amide. Diabetes 44: 16-19

9. Wang Z, Wang RM, Owji AA, Smith DM, Ghatei MA, Bloom SR (1995) Glucagon-like peptide-1 is a physiological incretin in rat. J Clin Invest 95: 417-421

10. D'Alessio DA, Vogel RL, Prigeon RL et al. (1996) Elimination of the action of Glucagon-like Peptide 1 causes an impairment of glucose tolerance after nutrient ingestion in healthy baboons. J Clin Invest 97: 133-138

11. Seltzer HS, Allen EW, Herron AL, Brennan MT (1998) Insulin secretion in response to glycemic stimulus: relation of delayed initial release to carbohydrate intolerance in mild diabetes mellitus. J Clin Invest 46: 323-335

12. Bruce DG, Chisholm DJ, Storlien LH, Kraegen EW (1988) Physiological importance of deficiency in early prandial insulin secretion in non-insulin-dependent diabetes. Diabetes 37: 736-744

13. Groop PH, Melander A, Groop LC (1993) The relationship between early insulin release and glucose tolerance in healthy subjects. Scand J Clin Lab Invest 53: 405-409

14. Willms B, Werner J, Holst JJ, Oerskov C, Creutzfeldt W, Nauck MA (1996) Gastric emptying, glucose responses, and insulin secretion after a liquid test meal: effects of exogenous glucagon - like peptide-1 (GLP-1)-(7-36) amide in type 2 (noninsulin-dependent) diabetic patients. J Clin Endocrinol Metab 81: $327-332$

15. Gutniak MK, Linde B, Holst JJ, Efendic S (1994) Subcutaneous injection of the incretin hormone glucagon-like peptide 1 abolishes postprandial glycemia in NIDDM. Diabetes Care 17: 1039-1044

16. Ritzel U, Orskov C, Holst JJ, Nauck MA (1995) Pharmacokinetic, insulinotropic, and glucagonostatic properties of GLP-1 (7-36 amide) after subcutaneous injection in healthy volunteers. Dose-response-relationships. Diabetologia 38: 720-725 
17. Nauck MA, Kleine N, Orskov C, Holst JJ, Willms B, Creutzfeldt W (1993) Normalization of fasting hyperglycaemia by exogenous glucagon-like peptide 1 (7-36 amide) in type 2 (noninsulin-dependent) diabetic patients. Diabetologia 36: 741-744

18. Ahren B, Larsson H, Holst JJ (1997) Effects of glucagon-like peptide-l on islet function and insulin sensitivity in noninsulindependent diabetes mellitus. J Clin Endocrinol Metab. 82: 473-478

19. Rachman J, Barrow BA, Levy JC, Turner RC (1997) Near-normalization of diurnal glucose concentrations by continuous administration of glucagon - like peptide-1 (GLP-1) in subjects with NIDDM. Diabetologia 40: 205-211

20. Drucker DJ (1998) Glucagon-like peptides. Diabetes 47: 159-169

21. Gutniak M, Larsson H, Heiber M, Juneskans, OT, Holst JJ, Ahren B (1996) Potential therapeutic levels of glucagon-like peptide 1 achieved in humans by a buccal tablet. Diabetes Care 19: 843-848

22. Deacon CF, Johnsen AH, Holst JJ (1995) Degradation of glucagon-like peptide- 1 by human plasma in vitro yields an $\mathrm{N}$-terminally truncated peptide that is a major endogenous metabolite in vivo. J Clin Endocrinol Metab 80: 952-957

23. Deacon CF, Pridal L, Klarskov L, Olesen M, Holst JJ (1996) Glucagon - like peptide 1 undergoes differential tissue-specific metabolism in the anesthetized pig. Am J Physiol 271: (Pt. 1), E458-E464

24. Holst JJ , Hansen L, Orskov C, Wojdemann M, Wettergren A, Deacon CF (1998) GLP-1 (7-36 amide) is transformed by dipeptidyl peptidase IV in the capillaries supplying the L-cells into GLP-1 (9-36 amide), which antagonizes the gastrointestinal effects of GLP-1. Diabetes 47:A30

25. Nauck MA, Wollschlaeger D, Werner J et al. (1996) Effects of subcutaneous glucagon - like peptide 1 (GLP-1 [7-36 amide]) in patients with NIDDM. Diabetologia 39: 1546-1553

26. Hughes TE, Mone MD, Russell ME, Weldon SC, Villhauer EB (1999) NVP-DPP728 (1-[2-[(5-cyanopyridin-2-yl)amikno]ethylamino]acetyl-2-cyano-(S)-pyrrolidine), a slow-binding inhibitor of dipeptidyl peptidase IV. Biochemistry (in press)

27. Orskov C, Rabenhoj L, Wettergren A, Kofod H, Holst JJ (1994) Tissue and plasma concentrations of amidated and glycine-extended glucagon-like peptide I in humans. Diabetes 43: $535-539$

28. Orskov C, Jeppesen J, Madsbad S, Holst JJ (1991) Proglucagon products in plasma of noninsulin-dependent diabetics and nondiabetic controls in the fasting state and after oral glucose and intravenous arginine. J Clin Invest 87: 415-423

29. Deacon CF, Hughes TE, Holst JJ (1998) Dipeptidyl peptidase IV inhibition potentiates the insulinotropic effect of glucagonlike peptide 1 in the anesthetized pig. Diabetes 47: 764-769

30. Kubota T, Flentke GR, Bachovchin WW, Stollar BD (1992) Involvement of dipeptidyl peptidase IV in an in vivo immune response. Clin Exp Immunol 89: 192-197

31. Holst JJ, Deacon CF (1998) Inhibition of the activity of dipeptidyl-peptidase IV as a treatment for type II diabetes mellitus. Diabetes 47: in press

32. Porte D Jr (1991) Banting Lecture 1990: B-Cells in Type II Diabetes Mellitus. Diabetes 40: 166-180

33. Nauck MA, Heimesaat MM, Orskov C, Holst JJ, Ebert R, Creutzfeldt W (1993) Preserved incretin activity of glucagonlike peptide 1 [7-36 amide] but not of synthetic human gastric inhibitory polypeptide in patients with type- 2 diabetes mellitus. J Clin Invest 91: 301-307

34. Kieffer TJ, McIntosh CH, Pederson RA (1995) Degradation of glucose-dependent insulinotropic polypeptide and truncated glucagon-like peptide 1 in vitro and in vivo by dipeptidyl peptidase IV. Endocrinology 136: 3585-3596

35. Wettergren A, Wojdemann M, Holst JJ (1998) The inhibitory effect of glucagon-like peptide-1 (7-36)amide on antral motility is antagonized by its N-terminally truncated primary metabolite GLP-1 (9-36)amide. Peptides 19: 877-882

36. Knudsen LB, Pridal L (1996) Glucagon - like peptide-1-(9-36) amide is a major metabolite of glucagon - like peptide - 1 (7-36) amide after in vivo administration to dogs, and it acts as an antagonist on the pancreatic receptor. Eur J Pharmacol 318: 429-435

37. Chua SC Jr, White DW, Wu-Peng XS et al. (1996) Phenotype of fatty due to Gln269Pro mutation in the leptin receptor (Lepr). Diabetes 45: 1141-1143

38. Brozinick JT Jr, Etgen GJ Jr, Yaspelkis BB 3rd, Ivy JL (1994) Glucose uptake and GLUT-4 protein distribution in skeletal muscle of the obese Zucker rat. Am J Physiol 267:R236-R243

39. Brozinick JT Jr, Etgen GJ Jr, Yaspelkis BB 3rd, Kang HY, Ivy JL (1993) Effects of exercise training on muscle GLUT-4 protein content and translocation in obese Zucker rats. Am J Physiol 265: E419-E427

40. Penicaud L, Ferre P, Assimacopoulos JF et al. (1991) Increased gene expression of lipogenic enzymes and glucose transporter in white adipose tissue of suckling and weaned obese Zucker rats. Biochem. J 279: 303-308

41. Hatanaka S, Kondoh M, Kawarabayashi K, Furuhama K (1994) The measurement of gastric emptying in conscious rats by monitoring serial changes in serum acetaminophen level. $\mathrm{J}$ Pharmacol Toxicol Methods 31: 161-165

42. Sanaka M, Koike Y, Yamamoto T et al. (1997) A reliable and convenient parameter of the rate of paracetamol absorption to measure gastric emptying rate of liquids. Int J Clin Pharmacol Ther 35: 509-513

43. Schirra J, Katschinski M, Weidman C et al. (1996) Gastric emptying and release of incretin hormones after glucose ingestion in humans. J Clin Invest 97: 92-103

44. Young AA, Gedulin, BR, Rink TJ (1996) Dose-responses for the slowing of gastric emptying in a rodent model by glucagon-like peptide (7-36) NH2, amylin, cholecystokinin, and other possible regulators of nutrient uptake. Metabolism 45: 1-3

45. Balkan B, Kwasnik L, Miserendino R, Li X (1998) Effects of DPP-IV inhibition on oral glucose tolerance - Comparison with GLP-1 and GIP injections (Abstract). -34th Ann. Meeting of the European Association for the Study of Diabetes, Pancreatic $\beta$-cell and islet research 1998- EASD Islet Study Group, S'Agaro, Girona, September 13-14, 1998. Endocrinologia 45: 269

46. Balkan B, Kwasnik L, Miserendino R, Mone M, Hughes TE, Li $\mathrm{X}$ (1997) Improved insulin secretion and oral glucose tolerance after In vivo inhibition of DPP-IV in obese Zucker rats. 16th International Diabetes Federation Congress, Helsinki, Finland, July 20-25, 1997. Diabetologia 40: 511, A131 (Abstract)

47. Pederson RA, White HA, Schlenzig D, Pauly RP, McIntosh CHS, Demuth H-U (1998) Improved glucose tolerance in Zucker fatty rats by oral administration of the dipeptidylpeptidase IV inhibitor isoleucine thiazolidide. Diabetes 47: $1253-1258$

48. Mentlein R, Gallwitz B, Schmidt WE (1993) Dipeptidyl-peptidase IV hydrolyses gastric inhibitory polypeptide, glucagonlike peptide-1(7-36)amide, peptide histidine methionine and is responsible for their degradation in human serum. Eur J Biochem 214: 829-835 